\title{
L2 reading and vocabulary development after a short Study Abroad experience
}

\author{
Judith Borràs \\ jborras@dal.udl.cat \\ Àngels Llanes \\ allanes@dal.udl.cat \\ Department of English and Linguistics, Universitat de Lleida, Spain
}

\begin{abstract}
This study explores the development of L2 reading and vocabulary as a result of a short (3-week) SA experience. Given the growing literature on Study Abroad (SA) research, this investigation attempts to shed some light on two rather under-researched areas such as L2 reading and vocabulary, and it does so with a group of adolescents $(n=52)$, a population often neglected by the SA research despite being one of the most common participants in SA programmes. The participants, Spanish learners of English (L2), were administered a placement test to determine their initial L2 level, a reading text (from which fluency and comprehension were calculated), the Updated Vocabulary Level Test to measure their receptive vocabulary knowledge, and a written essay to capture their productive vocabulary development in terms of lexical accuracy, fluency, density and sophistication. The results indicate that short SA experiences are positive for both reading fluency and comprehension as well as for receptive vocabulary development. Findings are not so positive in terms of productive vocabulary skills. Finally, results failed to show a direct relationship between gains in reading, and initial proficiency and vocabulary level.
\end{abstract}

Keywords: Study Abroad, reading development, vocabulary development, learning context, proficiency level

\section{Resumen}

Este estudio explora el desarrollo de las habilidades lectoras y la adquisición de vocabulario en una segunda lengua (L2) como resultado de una estancia corta (3 semanas) en el extranjero. Dado que se está dando mucha importancia a la 
investigación de las estancias en el extranjero, este proyecto pretende dar envergadura a dos áreas comúnmente ignoradas como son la lectura y el vocabulario. Lo hace con un grupo de adolescentes $(n=52)$, un grupo poco investigado en cuanto a la investigación de las estancias en el extranjero a pesar de ser unos de los participantes más comunes en éstas. A los participantes, españoles estudiantes de inglés como L2, se les administró un test para saber su nivel inicial en la L2, un examen de lectura (para saber su fluidez y comprensión), el Updated Vocabulary Level Test para medir su vocabulario receptivo, y una redacción para capturar su vocabulario productivo (en cuanto a precisión, fluidez, densidad y complejidad). Los resultados indican que las experiencias en el extranjero, aunque sean cortas, son positivas para la fluidez y la comprensión lectora y también en cuanto a vocabulario receptivo. Por lo que hace a la mejora de vocabulario productivo, los participantes sólo mejoraron significativamente su precisión a la hora de usar la L2. Finalmente, los resultados muestran que no hay una relación directa entre la mejora de la lectura y el nivel inicial, y el vocabulario inicial de los participantes.

Palabras clave: Estancias en el Extranjero, lectura, L2, vocabulario, contexto de aprendizaje, nivel de competencia

\section{Introduction}

Study Abroad (SA) experiences, especially those undertaken during the summer break, are gaining much popularity today, probably because it is believed that they provide a language immersion that is essential in order to learn or improve a second or foreign language (L2) (Dewey, 2004; Kinginger, 2009).

Despite the growing importance of these short stays, little research has been carried out investigating their effects on L2 gains (Llanes, 2011), since most of the SA research has focused on the effects of semester-long SA programmes. Moreover, the vast majority of research on SA examines the effect of these stays on university students and research with adolescents is rather scarce (Evans \& Fisher, 2005). Another remarkable fact is that the scant research available on the impact of a short SA experience has focused on skills such as oral fluency or pragmatics (Llanes \& Muñoz, 2009; Reynolds-Case, 2013), leaving other L2 areas such as reading and lexical development in a second place. Hence, although findings seem to be positive for some L2 areas such as oral fluency, some other areas are still rather under-researched. One such neglected area is L2 reading. The very few authors who have decided to examine the effects of SA programmes on the development of reading skills have done so with participants engaged in a long (+8 weeks) SA experience (Dewey, 2004; Li, 2014; Kraut, 2016), and these studies include university students. To the authors' knowledge, there 
is no study focusing exclusively on the impact of a short SA overseas experience on adolescents' L2 reading despite the fact that SA experiences lasting 2-3 weeks are the most popular among young adults and adolescents. This lack of research in reading is rather surprising considering that reading is one of the most important skills as it provides access to information (Grabe, 2009).

Another domain that plays a very important role in learning an L2 is vocabulary. As Nation (2006) and Schmitt (2008) claim, it takes much vocabulary to use a language well. This is particularly true for reading, "being the lack of lexical knowledge a major obstacle for successful comprehension even for advanced learners" (Zaytseva, 2016:45). Previous research has shown that vocabulary knowledge is related to reading development (Grabe, 2009; Li \& Kirby, 2014), so examining the impact of an SA experience on lexical knowledge is necessary when analysing the SA impact on reading. Although some of the studies that have analysed the effect of an SA experience on vocabulary development report positive results (Ife, Vives, Boix, \& Meara, 2000; Briggs, 2015), these studies have explored the effects of longer SA experiences (3-4 months) and only very few studies to date have examined the effect of a short SA (3-4 weeks) experience on vocabulary development. One of such studies is Llanes and Muñoz (2009), but the authors only included two vocabulary measures, namely oral lexical complexity and lexical errors. Therefore, more in-depth studies examining the impact that a short SA experience has on L2 vocabulary acquisition are needed.

All in all, given the popularity of short SA programmes and the paramount importance of L2 vocabulary and reading proficiency, the present study aims at examining whether a 3-week SA experience will lead participants to 1) improve reading comprehension and reading rate, 2) learn new L2 words and enabling them to use L2 lexicon more efficiently when producing a written task, and 3) to investigate if there is a relationship between gains in participants' $L 2$ reading skills (if any) and their initial vocabulary knowledge and proficiency level.

\section{Literature review}

\subsection{SA and $\mathrm{L} 2$ reading development}

Generally, students who participate in SA experiences travel to countries where they can be fully immersed in the language in order to practise the L2 and assuming the L2 will improve. However, SA research has revealed that not all L2 areas are positively affected after an overseas experience. Although many studies conclude that SA is a good weapon towards language improvement (Juan-Garau, 2014; Michell, Tracy-Ventura, \& 
McManus, 2017), the same attention has not been given to all the L2 areas: There are many studies on oral skills (George, 2014; Llanes, Mora, \& Serrano, 2016), but other areas such as reading require further investigation. As Kinginger (2009:61) stated "competence in reading is remarkably under-represented in the applied linguistics literature related to study abroad”.

Apart from the lack of studies investigating the $\mathrm{L} 2$ reading development after an SA experience, another conspicuous problem is that the findings of these studies are unclear, which makes it difficult to draw decisive conclusions on whether SA has a positive impact on L2 reading. Dewey (2004), for example, analysed the L2 reading development of 30 North-American students, learners of Japanese as an L2. Half of the participants enrolled in an Intensive Immersion (IM) course in the United States, while the other half joined a SA course in Japan. Although Dewey analysed reading comprehension using three different measures (free-recall protocols, vocabulary knowledge tests and self-assessment) significant differences between the SA and the IM group were only found regarding the participants' self-assessment. More specifically, the author found that learners in the SA programme felt more confident with their reading skills after spending 11 weeks in the target country than those students who participated in the IM course. These results indicate that SA may be positive for reading skills, nonetheless, results focused exclusively on students' perceptions and there is no data providing actual information that the SA students were in fact better at reading by the time they went back to the U.S.A. A year later, Evans and Fisher (2005) examined the impact that a short (6-11 days) SA experience had on a group of English secondary school students, learners of French as an L2 ( $n=68)$. The authors attempted to provide evidence of the impact that participating in a school exchange programme had on the participants' French proficiency. They concluded that such a short period of time may provide significant gains in listening and writing skills but no meaningful influence was found in terms of L2 reading or speaking, suggesting that short SA programmes do not provide enough practise for learners to improve their L2 reading skills. More promising results come from Li (2014), who investigated the L2 reading development of six groups of North-American undergraduates, learners of Chinese $(n=73)$, over an 8-week SA experience in China. Li's groups consisted of a beginner group at home $(\mathrm{AH})$ and another one $\mathrm{SA}$, an intermediate group $\mathrm{AH}$ and their SA counterparts, and an advanced group AH and their SA counterparts. The author examined the participants' reading comprehension skills and their use of strategies when reading in Chinese. Li found that, generally, the SA groups outscored those AH in all the measures analysed. Hence, the author concluded that SA was positive for both $\mathrm{L} 2$ reading comprehension and strategy use, with intermediate students showing the greatest gains. In a more recent study, Kraut (2017) examined a group of 16 Arabic and Chinese students, learners of L2 English, who were enrolled in an 8-week long 
Intensive English Programme (IEP) in the U.S.A. The author investigated the effects of SA on lexical inferencing abilities, vocabulary breadth, reading comprehension and reading speed, and participants' attitudes towards reading. Kraut's results show a positive picture for participants' reading speed, willingness to read out of curiosity and students' perceived self-efficacy. It must be highlighted, though, that participants in Kraut's study participated in an IEP programme, which involves more hours of instruction per week (Kraut, 2017) than traditional SA programmes. Hence, the combination of the intensity of instruction and SA indicate that IEPs may provide greater chances for learning to occur. All in all, the impact that SA programmes have on $\mathrm{L} 2$ reading skills is still somewhat blurred and no conclusions can be drawn to determine whether living in the target community aids the development of the reading skill. Moreover, most of the studies which have investigated this skill have a duration of +8 weeks and are conducted with undergraduate students. There is only one study to date analysing the effects that a shorter SA programme may have on the L2 reading development with group of adolescents (Evans \& Fisher, 2005) and it does so in a very broad manner: it not only focused on reading skills but on L2 development in general, including listening, reading, writing and speaking). Therefore, it only provides an overview of the development of students in each area and, consequently, more studies investigating if short SA experiences influence L2 reading positively are needed.

\subsection{SA and L2 vocabulary development}

Several authors have claimed that readers need a large amount of vocabulary in order to understand a text well (Hu \& Nation, 2000; Nation, 2006; Schmitt, 2008). Not knowing the meaning of certain words in a text can be a major obstacle for reading fluency since readers will not be able to read at their normal speed if they have to stop because of their lack of vocabulary knowledge (Beglar, Hunt, \& Kite, 2012; Huffmann, 2014). Since previous studies on SA have found that vocabulary is one of the areas positively influenced after an SA, it is plausible that this improvement in L2 vocabulary (if any) could be reflected in the participants' reading skills.

A growing number of studies have examined the impact of SA on L2 lexical knowledge (Ife, Vives-Boix, \& Meara, 2000; Foster, 2009; Pérez-Vidal \& Barquin 2014; Zaytseva 2016). As an illustration, Barquin (2012) analysed the written vocabulary development of a group of 30 Catalan/Spanish bilinguals, learners of English as an L2 first AH and, then, abroad. She concluded that the period abroad was significantly favourable for productive vocabulary development. Another relevant study on SA and vocabulary is that by Briggs (2015), in which the author explored if out-of-class activities affected gains in receptive and productive vocabulary. Participants in her study $(n=241)$ had different first languages and studied English in the UK for different 
periods of time (short $=6-10$ weeks, medium $=11-15$ weeks, long $=16-20$ weeks). Briggs concluded that SA led to gains in vocabulary breadth although she found that these gains were not related to place or out-of-class contact. The author also claimed that length of stay was an important predictor of language gains: "the longer a learner spends in the study abroad context, the higher their gains" (2015:137) with participants staying for 6-10 weeks improving their receptive vocabulary significantly but failing to show gains regarding productive vocabulary. Another study that examined the impact of an SA experience on vocabulary is Tracy-Ventura (2017), who explored the lexical sophistication of a group of 27 L1-English learners of Spanish in Spain and Mexico. The author found that participants improved significantly their knowledge of low frequency words after their 9-month-long SA experience. Moreover, statistically significant changes were also found with regards to participants' actual use of these words indicating that participants not only learnt low frequency words, but they also used them more. Altogether, this study provides positive evidence of SA and lexical knowledge. Noticeably, it can be stated that SA is beneficial for vocabulary development as there are many different examples which prove it. Nonetheless, as in the case of reading, none of them investigates the vocabulary development of teenagers as a result of a short overseas experience. Moreover, the few studies which have examined the effects of a short SA experience on L2 vocabulary (Llanes, 2012; Serrano, Llanes, $\&$ Tragant, 2016) do not focus exclusively on vocabulary (they examine different L2 domains) and, hence, no study has included a relatively wide range of measures of L2 receptive and productive vocabulary, which would provide more robust results.

There is evidence that short ( $\leq 5$ weeks) SA experiences have a positive impact on several L2 areas, such as oral skills (Llanes \& Muñoz, 2009), pragmatic development (Reynolds-Case, 2013), listening comprehension (Cubillos, Chieffo, \& Fan, 2008; Rodrigo, 2011), pronunciation (Llanes, Mora, \& Serrano, 2016), and writing skills (Evans \& Fisher, 2005). However, there is no single study, to the authors' knowledge, that looks at the impact that such a short SA experience has on L2 vocabulary, and there is only one that includes reading development (Evans \& Fisher, 2005), although learning vocabulary is usually among the short-SA participants' goals (Allen, 2010) and reading is one of the most important skills (Rasinski, 2003). There are reasons to think that both skills would improve after an SA experience. One of such reasons is the intensive exposure that SA participants experience while overseas, and previous research has found that intensive experiences are conducive to L2 gains (Muñoz, 2012). Another reason for potential gains in vocabulary is the ample opportunities for practise, and practise has been found to be a key factor when improving the L2 (DeKeyser, 2007). However, the impact that the SA context has on L2 reading development is especially interesting because this skill is hardly ever (extensively) practised while abroad, and simply being in the target country may not guarantee that 
students improve this skill. It is plausible to think that SA participants have chances of improving their L2 vocabulary repertoire because, apart from the amount of exposure and practise that characterize the SA context, participants use the L2 for real purposes, and this may result in an improvement in vocabulary. It is also reasonable to think that if there is an improvement in vocabulary, this improvement can positively affect reading skills, at least as far as reading fluency and comprehension are concerned. However, whether three weeks is enough for gains in L2 reading and vocabulary to occur is unknown. Previous studies examining the impact of a specific treatment on L2 vocabulary development (not necessarily in a SA context) have found gains in as short a period of time as three to six days (Beck \& McKeown, 2007), two weeks (Kaivanpanah \& Rahimi, 2017) or one or two semesters (Ife, Vives, Boix, \& Meara 2000). Hence, it is likely that there is improvement in vocabulary after three weeks overseas. Nonetheless, the dearth of research in the area makes it difficult to draw robust conclusions on whether short SA experiences are positive for participants' L2 reading and vocabulary development.

Thus, in order to fill these existing gaps in the literature, the current study addresses the following questions:

1. Does a 3-week SA experience have a positive impact on L2 reading development in terms of comprehension and fluency?

2. Does a 3-week SA experience have a positive impact on L2 receptive vocabulary development (measured through the Updated VLT) and productive vocabulary development (measured through lexical fluency, lexical accuracy, lexical density and lexical sophistication)?

3. Are gains in L2 reading (in terms of comprehension and fluency) related to initial L2 vocabulary knowledge and proficiency level?

\section{Method}

\subsection{Participants}

Fifty-two teenagers ( $n=25$ males, $n=27$ females), learners of English as an L2 participated in the present study. Their ages ranged between 12 and 17 years old $(\mathrm{M}=$ 15,35) and all came from different regions of Spain but one, who came from Andorra. All the participants started learning English at primary school and their levels by the time they started the SA experience ranged from A2 to B2 (A2 n=31, B1 n= 17 and B2 $n=4)$. The students enrolled in a 3-week summer programme in Ireland which fostered 
communication in English. All the participants lived with a host family and attended classes Monday through Friday for 4 hours per day during the mornings. The teachers were all native English speakers and the activities carried out in the classrooms were very dynamic and consisted in playing games, performing some debates, and completing some worksheets, among others. When classes finished, students were given one hour to have lunch and then they spent two more hours at the school carrying out different activities with the teachers: Irish workshops, Irish sports, arts and crafts, or visiting some tourist places. After the afternoon activities students spent the evenings with their host families, with whom they performed different activities.

\subsection{Instruments}

The Oxford Quick Placement Test (OPT) was used to examine participants' overall L2 proficiency. This test has been widely used by researchers (Llanes et al., 2016) and it has proved to be a reliable instrument to examine L2 proficiency. The test contains two sections, but only the "Use of English" one was used during the data collection. This part consisted of 60 multiple choice items with three or four possible answers, and one point was given per correct item.

Two texts of different proficiency levels were chosen to measure participants' reading fluency and comprehension. Following Kraut (2017), both texts were taken from the Reading Explorer, a book that contains texts of different lengths and diverse topics. The texts are followed by some comprehension questions. To make sure that the texts targeted different L2 levels and that they were suitable for the participants, their readability index was also calculated. The first was taken from the Reading Explorer 2, which contains texts of an A2 level according to the Common European Framework of Reference for Languages (CEFR). The readability test showed a 72.3 in Flesh reading ease, which means that the difficulty of the text was equivalent to texts generally used during the first year of secondary education. The second text was taken from the Reading Explorer 3, which contains texts of a B1 CEFR level. This B1 text obtained a 52.8 in Flesh reading ease, indicating that the difficulty of the text was similar to texts read during the last years of secondary education and the A levels. Each text was followed by a set of multiple choice questions. Although most of the questions came from the Reading Explorer book, some were slightly changed and some others were added by the authors (the added questions were previously piloted). After determining the participants' initial proficiency level, it was decided that only the data of the A2 text would be considered for the present study given that previous research shows that one requirement to measure reading rates is text suitability: the text has to be well within the students' capability (Carver, 1990; Huffman, 2014). 
Two instruments were used to gauge participants' lexical knowledge: the Updated Vocabulary Levels Test (VLT) (Webb, Sasao, \& Balance, 2017) and a writing task. The Updated VLT measures receptive vocabulary and has been widely used in the research of L2 lexical knowledge (Briggs, 2015). This test is divided into five levels (K1, K2, K3, K4 and K5) and words are provided in sets of six words with three possible definitions; participants have to match the items with their proper definition (with the three remaining words as distractors). There are 30 definitions per level and five levels in total, which amounts to 150 definitions. The writing task measured productive vocabulary. Since researchers who have analysed vocabulary claim that much data can be gathered from a written text (Zaytseva, 2016; Tracy-Ventura, 2017) it was believed that this task would be a reliable tool to gather data for lexical knowledge and lexical error analysis. Participants were allotted fifteen minutes to write a text entitled "My life: past, present and future expectations" (Llanes \& Serrano, 2014) and no specific word limit was required. It must be highlighted that productive vocabulary was measured through a written test, but writing skills development (i.e. grammar, complexity or syntax) was not the focus of the present study.

In order to triangulate the data, the researcher who conducted the pre- and post- tests also spent some time observing the participants in their classes, afternoon activities, weekends and with their families. Moreover, the researcher also interviewed, informally, some of the teachers and students in order to have more information on the overall learning experience.

\subsection{Procedure}

This study has a pre- and post-test design. The tests were exactly the same for the preand post-test. However, participants were not informed about the focus of the research and that there would be a post-test so that this could not affect the results. Both tests were administered in Ireland: the pre-test was administered on the third day into the SA programme, and the post-test two days before the students' departure to Spain. Thus, the stay lasted 3 weeks, but the time elapsed between the pre- and post-test was 15 days. The procedure was the same at both times, the only difference being that in the pre-test students were asked to fill out a personal information sheet before administering the tests. First, the two texts were administered. A chronometer was projected on the front screen of a digital board so that everyone could see it. Then, the participants were given a text to read and, once they had finished, they were asked to look at the chronometer and write down the time they had taken to read it (minutes and seconds). Participants were informed that they could only read the text once, that they would not have the text when answering the comprehension questions, and that they were asked to read the text at their normal speed. In order to counterbalance any task-effects, half of the 
participants started reading the A2 text and the other half the B1 text (the students that started reading the $\mathrm{A} 2$ text in the pre-test also did so in the post-test, and the same was true for the B1 text). Afterwards, the texts were collected and the comprehension question sheet was administered. The students were not given any specific time to answer the questions and the researchers waited until all of them had finished to start with the next exercise, the written essay. Participants were asked to write a composition with the title "My life: past, present and future expectations" and they were allotted a total of 15 minutes. After the writing task, the students were asked to fulfil the Updated VLT, for which they were given a maximum of 20 minutes. Finally, participants were administered the OPT and they were given 30 minutes. Once they had finished the OPT, the data collection was completed and students were given permission to leave the room. The whole data collection procedure took approximately 90 minutes.

\subsection{Measures}

Reading fluency was measured through words per minute (WPM). The following formula was used to compute WPM: 504 (which is the number of words the text had) x 60 seconds/ total time in seconds students took to read the text. Concerning reading comprehension, the number of correct answers out of 13 was used to measure text comprehension.

As for receptive vocabulary, the updated VLT provided information about the participants' lexical knowledge in terms of receptive vocabulary knowledge. The test included 150 target words, so the raw score out of 150 was calculated. With regards to productive vocabulary, the measures in the present study were adopted following Zaytseva (2016). The Computerized Language Analysis (CLAN) software was used to measure lexical fluency and accuracy. The programme provided the total number of types, tokens and lexical errors the students had made in the texts and with this information the participants' lexical fluency and accuracy were calculated. Lexical fluency was measured through tokens (i.e. total number of words used to write the text) and lexical accuracy was measured by counting the amount of lexical errors in the text and dividing them by the total number of tokens. In order to calculate the participants' lexical density and sophistication the online tool VocabProfile was used. Lexical density consisted of the percentage of content words (nouns, verbs, adjectives and adverbs) in the text. To measure lexical sophistication, the number of "rare" words that participants used within the text (words from the 6000 frequency level or above) was used to see whether they used words from a higher frequency level (i.e. more sophisticated) in the post-test writings. Finally, the CEFR level of the participants was calculated by the total number of points they obtained from the OPT (see Table 1 for a summary of the measures used). 
Higher values in the post-test were expected for all the measures except for lexical accuracy, since lower values in this measure would mean that participants had made fewer lexical errors in their post-writings. In terms of lexical sophistication, a lower percentage of words from the 1000 frequency level would also indicate that participants' texts were more sophisticated by the time they left the host country.

Table 1: Summary of measures

\begin{tabular}{lll}
\hline Domain & Measure-Test & Formula \\
\hline General proficiency & OPT & Raw score $/ 60$ \\
\hline Reading fluency & WPM - reading text & $\begin{array}{l}504^{*} 60 / \text { Total seconds } \\
\text { taken to read the text }\end{array}$ \\
\hline Reading comprehension & $\begin{array}{l}\text { Comprehension - reading } \\
\text { text }\end{array}$ & Raw scores $/ 13$ \\
\hline Receptive vocabulary & VLT & Raw scores $/ 150$ \\
\hline \multirow{3}{*}{ Productive vocabulary } & $\begin{array}{l}\text { Lexical fluency - written } \\
\text { essay }\end{array}$ & \begin{tabular}{l} 
Total number of tokens \\
\cline { 2 - 3 }
\end{tabular} \\
$\begin{array}{l}\text { Lexical accuracy - written } \\
\text { essay }\end{array}$ & $\begin{array}{l}\text { Number of lexical errors/ } \\
\text { tokens }\end{array}$ \\
\cline { 2 - 3 } & $\begin{array}{l}\text { Lexical density - written } \\
\text { essay }\end{array}$ & $\begin{array}{l}\text { Number of content } \\
\text { words/tokens }\end{array}$ \\
\cline { 2 - 3 } & $\begin{array}{l}\text { Lexical sophistication - } \\
\text { written essay }\end{array}$ & $\begin{array}{l}\text { Comparison of the } \\
\text { percentages from words of } \\
\text { different frequency levels }\end{array}$ \\
\hline
\end{tabular}

\section{Results}

When checking the normality of the data, most of the measures violated the assumption of normality. Therefore, non-parametrical tests were run to answer the first and second research questions. However, before running any tests, the data were coded independently by the first author of the present study and by another expert to ensure inter-rater reliability. The two encodings were compared and they reached an agreement of $92.31 \%$. Intra-rater reliability was also calculated, and the level of agreement was exactly the same $(92.31 \%)$. Inter- and intra-rater reliability were only calculated for lexical errors given that it was the only measure that could vary depending on the rater. 
The first research question asked whether a 3-week SA experience had a positive impact on $\mathrm{L} 2$ reading development in terms of comprehension and fluency. In order to answer this question, a Wilcoxon signed-rank test was run to observe if there were significant differences between the scores in the pre-test and those in the post-test. As shown in Table 2 below, participants improved on both measures of reading (WPM and comprehension) from the pre- to the post-test, and the Wilcoxon test indicated that improvement was statistically significant for both: WPM ( $Z=-3.201, p=.001)$, and comprehension $(Z=-2.902, p=.004)$. The effect sizes for WPM and Comprehension were $d=0.492, d=0.55$, respectively, which indicate that this difference was medium (Cohen, 1988).

Table 2: Descriptive statistics

\begin{tabular}{lcccc}
\hline Measure & \multicolumn{2}{c}{ Pre-test } & \multicolumn{2}{c}{ Post-test } \\
\hline OPT & $\mathrm{M}$ & $\mathrm{SD}$ & $\mathrm{M}$ & $\mathrm{SD}$ \\
\hline WPM & 29.25 & 6.90 & 30.65 & 7.05 \\
\hline Comprehension & 118.65 & 33.29 & 134.60 & 32.73 \\
\hline VLT raw score & 6.73 & 1.87 & 7.54 & 1.83 \\
\hline Lexical fluency & 102.19 & 28.06 & 112.56 & 26.66 \\
\hline Lexical accuracy & 127.08 & 39.13 & 128.02 & 40.268 \\
\hline Lexical density & .037 & .024 & .013 & .014 \\
\hline 1000 Frequency Level & .45 & .043 & .45 & .045 \\
\hline$>$ 5000 Frequency & 90.69 & 4.25 & 91.71 & 3.66 \\
Level & 2.45 & 1.34 & 1.95 & .75 \\
\hline
\end{tabular}

The second research question addressed whether a 3-week SA experience had a positive impact on L2 lexical knowledge. Table 2 shows that participants improved their receptive vocabulary (VLT) and two measures of productive vocabulary (lexical fluency and accuracy). However, there was no improvement regarding lexical density and lexical sophistication. Again, a Wilcoxon signed-rank test was employed to see if these pre- to post-test differences were significant and it was found that their receptive vocabulary significantly improved from the pre- to post-test $(Z=-5.132, p=.000)$, but only one measure of productive vocabulary improved significantly, namely lexical accuracy $(Z=-5.689, p=.000)$. Therefore, the data show that participants learnt new words and made significantly fewer lexical errors in their post-test essays. However, 
although there seems to be a slight tendency for learners to produce longer essays, there was no significant difference in terms of lexical fluency between the essays before and after the stay. The effect sizes indicated that the difference for the two measures that changed significantly was medium for receptive vocabulary $(\mathrm{d}=0.365)$ and large for lexical accuracy $(\mathrm{d}=1.22)$.

The last research question asked whether gains in reading (both in terms of comprehension and fluency) were related to initial L2 proficiency and initial vocabulary knowledge. In order to answer this question, bivariate correlations were run between initial L2 level (OPT pre-test scores), initial L2 vocabulary level (pre-test raw scores of VLT) and gains in reading comprehension and fluency (to calculate the gains in comprehension and fluency, the score in these measures in the post-test was subtracted from the score in these measures in the pre-test). No significant correlations were found between any of the independent variables and gains in reading.

\section{Discussion}

The aim of this study was to document the impact of a 3-week SA experience on adolescents' L2 reading and vocabulary development as well as to examine to what extent gains in reading and vocabulary (if any) were related to L2 initial proficiency level and initial lexical knowledge. It was found that participants improved the two measures of L2 reading significantly, namely fluency and comprehension. Hence, the answer to our first research question is affirmative. Although the participants did not explicitly engage (much) in reading activities, they were massively exposed to English. This exposure, although not being through reading explicitly, may have been helpful for the students' reading development. As Gautier and Chevrot (2015:169) claimed, "Learning in contexts where the target language is used is considered particularly beneficial because such an environment should provide access to language that is ample in quantity and diverse in quality". Therefore, this intensive immersion in the L2 may have fostered the improvement of the participants' L2 reading skills (Muñoz, 2012).

These results are in line with Kraut (2017), who found that an 8-week-long SA experience had a positive impact on $\mathrm{L} 2$ reading skills. However, the present study shows that even shorter SA programmes (3 weeks) impact positively L2 reading development in terms of comprehension and fluency. The positive outcomes found in the present study could also be explained because of the participants' proficiency level. Previous studies show that participants with an advanced proficiency level do not progress as much as participants with a lower proficiency level, suggesting that the lower the participants' initial proficiency level, the more chances they have to improve it (Juan- 
Garau, 2014). Since most of the participants in the present study had an A2 or a B1 proficiency level, there was plenty of room for improvement and the measures used may have captured these gains. Another possible explanation to the positive outcomes in terms of reading is the intensity of instruction and/or the nature of SA experiences, which is a combination of formal in-class learning with informal out-of-class learning (afternoon activities and interaction with the members of the family).

The second research question asked whether a 3-week SA experience had a positive impact on $\mathrm{L} 2$ receptive and productive vocabulary. It was found that participants improved their receptive vocabulary significantly from the pre- to the posttest, and that they improved significantly one out of the four productive vocabulary measures, namely lexical accuracy. Therefore, results suggest that short SA experiences are positive in terms of learning new words and reducing lexical errors, but results also suggest that three weeks are not enough for participants to improve their lexical fluency, density and sophistication significantly. Hence, findings in the present study suggest that 3-week-long stays are not enough for learners to write significantly longer, denser and more sophisticated essays. All in all, the answer to the second research questions is affirmative in terms of receptive vocabulary, but its effects on productive vocabulary are not so promising. The reason for finding significant improvement in some vocabulary measures (receptive vocabulary and lexical accuracy) and not in others (lexical fluency, density and sophistication) might be the short time elapsed between the pre- and the post-test. It is possible that measures such as receptive vocabulary and lexical accuracy were more susceptible to gauging gains than other measures such as lexical density or sophistication, which might need more time to develop (in line with Briggs, 2015). With regard to receptive vocabulary, the results in the present study support Kraut (2017), who found similar results with her participants after an 8-week SA. In fact, a closer look at the VLT revealed that some participants learnt words such as 'sheet', 'alley' or 'forbid', which are likely to be encountered in an SA experience. Likewise, the lexical accuracy of the participants was also examined more closely. Table 3 includes excerpts of productions from the same participants in the pre and the post-test, where examples of lexical accuracy development can be clearly appreciated. Some of the lexical accuracy improvements SA students made involve a) appropriate distinction between words earlier treated as homophones (i.e. leave/live), b) reduction of made-up words (*tought/play), and c) more accurate lexical choice (travel/trip). 
Table 3. Examples of lexical accuracy from the same students' pre- to post-test

\begin{tabular}{lll}
\hline Student & Pre-test & Post-test \\
\hline Student A & $\begin{array}{l}\text { I leave in Palma. Before I leaved } \\
\text { in Madrid. }\end{array}$ & $\begin{array}{l}\text { I live in Palma. Before I lived in } \\
\text { Madrid. }\end{array}$ \\
\hline Student B & I tought the flut. & I play the flute. \\
\hline Student C & $\begin{array}{l}\text { I am the unic member of my } \\
\text { family who... }\end{array}$ & $\begin{array}{l}\text { I am the only member of my } \\
\text { family who... }\end{array}$ \\
\hline Student D & I am going to curse $3^{\text {rd }}$ of ESO. & I am going to do $3^{\text {rd }}$ of ESO. \\
\hline & & I loved this trip. \\
\hline
\end{tabular}

Other previous studies that have found gains in some of the productive vocabulary measures analysed in the present study are those by Pérez-Vidal and Barquin (2012) and Zaytseva (2016). These studies provide evidence that measures such as lexical fluency or density can be improved during an SA experience. Notwithstanding, there are three important differences between these studies and the present one: the duration of the programmes, the participants' age and their initial proficiency level. Participants in these studies engaged in a 3-month SA experience and they were university students with a higher initial L2 level. Previous research in the field of vocabulary has found that high gainers on comprehension made significantly larger gains in vocabulary (Shany $\&$ Biemiller, 2010). Hence, it is plausible that for productive vocabulary learning, a higher initial L2 level could have had a more positive impact. Given that reading and vocabulary are two different skills and the nature of the tests administered was also different, it is possible that participants with a lower L2 level improved reading comprehension and fluency more than vocabulary, whereas participants with a higher L2 level improved their vocabulary knowledge more. A tentative explanation for this latter hypothesis is that participants with a higher L2 level could possibly allocate their attention to other aspects of the L2 such as vocabulary. Finally, in terms of lexical sophistication, findings in previous studies seem to suggest that long periods abroad are needed in order for participants to show significant changes with regard to the measure. Zaytseva (2016), for example, found no significant difference for the size of gains in lexical sophistication after participants in her study had been abroad for three 
months. However, Tracy-Ventura (2017) found that after nine months abroad not only did her participants improve their knowledge of low frequency words, but they also started using these words more in their written and oral discourses. These results provide further evidence that measures such as lexical sophistication need more time to develop than others such as lexical accuracy.

The third research question enquired whether $\mathrm{L} 2$ reading gains were related to initial proficiency level and initial lexical knowledge, and no significant correlation was found between these variables. Hence, the present study failed to find a direct relationship between initial vocabulary knowledge and proficiency level, and gains in reading, which suggests that all participants held the same chances to improve their reading skills regardless of their initial vocabulary knowledge and proficiency level. This finding does not support Nation (1993) and Li and Kirby (2014), who reported a relationship between vocabulary knowledge and reading skills which implied that being proficient in one of the skills was the factor that helped the most when attempting to improve the other. The present study suggests that SA adolescents improve their reading comprehension and fluency regardless of their initial L2 grammar or vocabulary knowledge. This finding indicates that a short SA is positive for teenagers' reading skills and not only for those who have a specific proficiency level or vocabulary knowledge. Nonetheless, it must be highlighted that the proficiency level of participants in the present study ranged mostly from A2 to B1 and that different results could have emerged if participants had a more advanced level. Previous research has exhibited a certain contradiction regarding the precise level that participants in SA need to hold before starting their stays (the threshold level). Some scholars such as Llanes and Muñoz (2009) and Juan-Garau (2014) state that 'the lower, the better'. These researchers argue that participants with lower L2 skills have more room to learn and, hence, their improvement is easier to detect. On the other hand, other authors such as DeKeyser (2007) and George (2014) claim that participants should possess a good command on the L2 before starting their stay in order to make the most of the SA. The present study is taking a central position between these two groups of researchers since it shows that the initial vocabulary knowledge and the proficiency level of the participants are not related to gains in reading skills and that, therefore, the threshold level is not a variable that has a strong effect on reading and vocabulary gains. It is possible that factors such as motivation to learn, willingness to take advantage of the SA, living with a host family, the type of programme or the personality of the participants, among others, are the constituents which have helped participants in the present study to improve their reading comprehension and fluency (see also Saito et al., 2018). 


\section{Conclusion}

No previous studies exist on the L2 reading and vocabulary development of a group of teenagers engaged in a short SA experience. It was found that participants improved their L2 reading comprehension and fluency significantly, showing greater understanding of texts and a faster reading rate after the 3-week stay abroad. Moreover, the results in the present study show that participants significantly improved their receptive vocabulary knowledge, which indicates that they learnt a significant number of new words during their time abroad, and their lexical accuracy, which indicates that 3-week-long SA help learners use L2 words in a more accurate way. No significant differences were found concerning the remaining three productive measures examined (lexical fluency, lexical sophistication and lexical density), suggesting that 3-week SA programmes are not enough for students to write longer, denser and more sophisticated texts. Although the findings of the present study suggest that some measures of productive vocabulary (fluency, density and sophistication) need more time to develop, results also suggest that short SA programmes can have a positive feedback on L2 reading and vocabulary development.

However, this investigation has some limitations. One of the limitations is that it does not include a control group learning the L2 at home (AH). Although the inclusion of control groups has been questioned in the SA literature because of the large differences between the participants engaging in an overseas experience and those remaining $\mathrm{AH}$, it would be interesting that further research include a comparison group $\mathrm{AH}$ engaged in a course focused on reading. This way, the effects of exposure to the L2 could be compared to the effects of reading practise and more robust conclusions could be drawn. Another limitation is the lack of more precise information on the amount of input and practise experienced. In other words, it would be interesting to know the amount of time participants spent speaking, reading or writing in English and see if amount of time spent practicing the L2 explained gains in reading or vocabulary. Finally, although the researchers made an effort to avoid task-repetition effects (the inclusion of two reading tests, not informing the participants that there would be a post-test, and administering the reading texts at the very beginning of the data collection), it is still possible that using the same instruments in the pre- and posttest might have influenced the results. Despite these limitations, the present study is a relevant contribution to the field of SA as it sheds light on the impact that a 3-week SA experience has on the L2 reading and vocabulary development of a group of adolescents.

Given that the present study shows that a 3-week SA experience has a positive impact on the L2 reading development and on some measures of vocabulary development, short SA programmes should be promoted among teenagers. Moreover, considering 
that teenagers who undertake summer SA experiences of this type usually do so via private institutions, these SA experiences should be made affordable to teenagers so that they will be able to participate and boost their L2 skills.

\section{Acknowledgements}

This study was supported by grant 2017SGR1522. We would like to thank Ferran C. for letting us conduct the data collection at one of his summer courses abroad and for his efforts to make the process as easy as possible. Our thanks are extended to Suzanne and Billy, teachers of the Irish language school, for letting us conduct the data collection and for helping us throughout the process. We would also like to thank the leaders for their comments and help during the data collection. Finally, we would like to thank the editor and the reviewers of VIAL for their suggestions on this article.

\section{References}

Allen, H.W. (2010). Language-learning motivation during short-term study abroad: An activity theory perspective. Foreign Language Annals, 43(1), 27-49.

Barquin, E. L. (2012). Writing development in a study abroad context (Unpublished doctoral dissertation). Universitat Pompeu Fabra, Barcelona.

Beck, I.L., \& McKeown, M.G. (2007). Increasing low-income children's oral vocabulary repertoires through rich and focused instruction. The Elementary School Journal, 107(3), 251-271.

Beglar, D., Hunt, A., \& Kite, Y. (2012). The effect of pleasure reading on Japanese university EFL learners' reading rates. Language Learning, 62(3), 665-70.

Briggs, J. G. (2015). Out-of-class language contact and vocabulary gain in a study abroad context. System, 53, 129-140.

Carver, R. P. (1990). Reading rate: A review of research and theory. New York: Academic Press.

Cohen, J. (1988). Statistical power of analysis for the behavioural sciences. Lawrence Erlbaum Associates, Hillsdale.

Cubillos, J.H., Chieffo, L., \& Fan, C. (2008). The impact of short-term study abroad programs on L2 listening comprehension skills. Foreign Language Annals, 41(1), $157-185$.

Dekeyser, R. (2007). Practice in a second language: Perspectives from applied linguistics and cognitive psychology. Cambridge University Press. 
Dewey, D. (2004). A comparison of reading development by learners of Japanese in intensive and domestic immersion and study abroad contexts. Studies in Second Language Acquisition, 26, 303-327.

Evans, M., \& Fisher, L. (2005). Measuring gains in pupils' foreign language competence as a result of participation in a school exchange visit: the case of Y9 pupils at three comprehensive schools in the UK. Language Teaching Research, 9(2), 173-192.

Foster, P. (2009). Lexical diversity and native-like selection: the bonus of studying abroad. In B. Richards, H.M., Daller, D.D. Malver, P. Meara, J. Milton \& J. TreffersDaller (Eds.), Vocabulary Studies in First and Second Language Acquisition. (pp 91-106) Hampshire: Palgrave Macmillan.

Gautier, R., \& Chevrot, J.P. (2015). Social networks and acquisition of sociolinguistic variation in a study abroad context: A preliminary study. In R. Mitchell, N. Tracy-Ventura \& K. McManus (Eds.), Social Interaction, Identity and Language Learning during Residence Abroad. (pp 169-184) EuroSLA Monographs Series, 4. Amsterdam: The European Second Language Association.

George, A. (2014). Study abroad in central Spain: The development of regional phonological features. Foreign Language Annals, 47(1), 97-114.

Grabe, W. (2009). Reading in a second language: Moving from theory to practise. Cambridge Applied Linguistics.

Hu, M., \& Nation, I.S.P. (2000). Unknown vocabulary density and reading comprehension. Reading in a Foreign Language, 13(1), 403-430.

Huffman, J. (2014). Reading rate gains during a one-semester extensive reading course. Reading in a Foreign Language, 26(2), 17-33.

Ife, A., VivesBoix, G., \& Meara, P. (2000). The impact of study abroad on the vocabulary development of different proficiency groups. Spanish Applied Linguistics, 4(1), 55-84.

Juan-Garau, M. (2014). Oral accuracy growth after formal instruction and study abroad: Onset level, contact factors and long-term effects. In C. Pérez-Vidal (Ed.), Language Acquisition in Study Abroad and Formal Instruction Contexts. (pp 87-109) Amsterdam: John Benjamins Publishing Co.

Kaivanpanah, S. \& Rahimi, N. (2017). The effect of contextual clues and topic familiarity on L2 lexical inferencing and retention. Porta Linguarum, 27, 47-61.

Kinginger, C. (2009). Language learning and study abroad: A critical reading of research. Houndsmills, Basingstoke, UK: Palgrave/Macmillan 
Kraut, R. E. (2017). The development of L2 reading skills: A case study from an eight week intensive English program course. Dialogues: An interdisciplinary Journal of English Language Teaching and Research, 1(1), 25-43.

Li, L. (2014). Language proficiency, reading development, and learning context. Frontiers: The Interdisciplinary Journal of Study Abroad, 24, 73-92.

Li, M., \& Kirby, J.R. (2014). The effects of vocabulary breadth and depth on English reading. Applied Linguistics, 36(5), 611-634.

Llanes, A. (2011). The many faces of study abroad: An update on the research on L2 gains emerged during a study abroad experience. International Journal of Multilingualism, 8(3), 189-215.

Llanes, À. (2012). The short- and long-term effects of a short study abroad experience: The case of children. System, 40, 179-190.

Llanes, À., Arnó, E., \& Mancho-Barés, G. (2016). Is a semester abroad in a non-English speaking country beneficial for the improvement of English? The case of Erasmus students using English as a lingua franca. Special issue of The Language Learning Journal, 44(3), 292-303.

Llanes, À., Mora, J.C., \& Serrano, R. (2016). Differential effects of SA and intensive $\mathrm{AH}$ courses on teenagers. International Journal of Applied Linguistics, 27(2), 470-490.

Llanes, À., \& Muñoz, C. (2009). A short stay abroad: Does it make a difference? System, 37(3), 353-365.

Llanes, À., \& Serrano, R. (2014). The effectiveness of classroom instruction 'at home' vs. study abroad for learners of English as a foreign language attending primary, secondary school and university. The Language Learning Journal, 45(4), 434-446.

Mitchell, R., Tracy-Ventura., N., \& McManus, K. (2017). Anglophone students abroad: Identity, social relationships and language learning. New York: Routledge.

Muñoz, C. (2012). Intensive exposure experiences in second language learning. Multilingual Matters: Bristol (United Kingdom)

Nation, I.S.P. (2006). How large a vocabulary is needed for reading and listening? The Canadian Modern Language Review/La Revue canadienne des langues vivantes, 63(1), 59-82.

Pérez-Vidal, C., \& Barquin, E. (2014). Comparing progress in writing after formal instruction and study abroad. In. C. Pérez-Vidal (Ed.), Language Acquisition in Study Abroad and Formal Instruction Contexts (pp. 217-234). Amsterdam: John Benjamins Publishing Co. 
Rasinski, T.V. (2003). The fluent reader: Oral reading strategies for building word recognition, fluency, and comprehension. Better World Books Ltd (Dunfermline, United Kingdom)

Reynolds-Case, A. (2013). The value of shortlterm study abroad: An increase in students' cultural and pragmatic competency. Foreign Language Annals, 46(2), 311-322.

Rodrigo, V. (2011). Contextos de instrucción y su efecto en la comprensión auditiva y los juicios gramaticales: ¿Son comparables cinco semanas en el extranjero a un semestre en casa? Hispania, 94(3), 502-513.

Saito, K., Dewaele, J.M, Abe, M., \& In'nami, Y. (2018). Motivation, emotion, learning experience and second language comprehensibility development in classroom settings. Language learning. 68(3), 709-743.

Schmitt, N. (2008). Review article: Instructed second language vocabulary learning. Language Teaching Research, 12(3), 329-363.

Serrano, R., Llanes, À., \& Tragant, E. (2012). Examining L2 development in two short-term intensive programs for teenagers: Study abroad vs. "at home". System, 57, 43-54.

Shany, M., \& Biemiller, A. (2010). Individual differences in reading comprehension gains from assisted reading practice: Pre-existing conditions, vocabulary acquisition, and amounts of practice. Reading and Writing: An Interdisciplinary Journal, 23(9), 10711083.

Tracy-Ventura, N. (2017). Combining corpora and experimental data to investigate language learning during residence abroad: A study of lexical sophistication. System, 71, 35-45.

Webb, S., Sasao, Y., \& Balance, O. (2017). The updated vocabulary levels test: Developing and validating two new forms of the VLT. ITL International Journal of Applied Linguistics, 168(1), 33-69.

Zaytseva, V. (2016). Vocabulary acquisition in study abroad and formal instruction: An investigation on oral and written lexical development (Unpublished doctoral dissertation). Universitat Pompeu Fabra, Barcelona. 
